Research Paper:

\title{
Support Needs of Urban and Rural Elders in Kermanshah City, Iran
}

\author{
Vahab Karamivand ${ }^{1}$, Farideh Bastani ${ }^{1 *}$, Hamid Haghani
}

1. Department of Geriatric Nursing, School of Nursing \& Midwifery, Iran University of Medical Sciences, Tehran, Iran

2. Department of Biostatistics, School of Public Health, Iran University of Medical Sciences, Tehran, Iran.

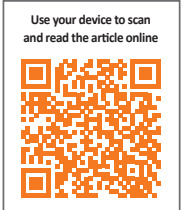

dtation Karamivand, V., Bastani, F. \& Haghani, H., 2018. Support Needs of Urban and Rural Elders in Kermanshah City, Iran. Journal of Client-Centered Nursing Care, 4(1), pp. 21-28. https://doi.org/10.32598/jccnc.4.1.21

https://doi.org/10.32598/jccnc.4.1.21

Funding: See Page 27

(cc) Copyright: The Author(s)

Article info:

Received: 10 Jun 2017

Accepted: 25 Oct 2017

Available Online: 01 Feb 2018

Keywords:

Supportive needs, Urban and rural elderly, Need assessment

\begin{abstract}
A B S T RA C T
Background: Demographic changes all over the world confirm an increase in elderly populations, who require assistance and support. In order to plan support services this study aimed to compare support needs of urban and rural elders who referred to health centres in Kermanshah City, Iran, in 2016.

Methods: The study design was descriptive-comparative. A total of 384 elderly (192 urban and 192 rural elderly) were selected by random cluster sampling method from all healthy elderly referring to health centers in Kermanshah. Data was collected by a demographic form and also the Supportive Care Need Scale to analyses the data, descriptive and inferential statistics were used. $\mathrm{P}$ value less than 0.05 was considered as statistically significant for all tests.

Results: The results of this study, using the Independent $t$ test, showed that the urban elders had more spiritual needs than the rural elderly $(\mathrm{t}=1.21, \mathrm{P}=0.02)$. Also, the results of the Chi-square test showed that the differences between the two groups of the participants regarding health care needs $(\mathrm{P}<0.01)$, educational $(\mathrm{P}<0.001)$, recreation $(\mathrm{P}<0.001)$ and transportation $(\mathrm{P}<0.01)$ are significant. But there were no significant differences between rural and urban elderly in the case of nutritional needs $(\mathrm{t}=0.072, \mathrm{P}=0.94)$, personal care $(\mathrm{P}=0.68)$, and housing $(\mathrm{P}=0.71)$.

Conclusion: According to the findings, designing educational programs for urban elders would be effective in meeting their spiritual needs. On the other hand, establishing recreational facilities, meeting their health needs and increasing the level of literacy in rural elderly are essential to
\end{abstract} prevent their social isolation.

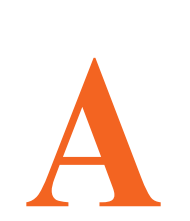

\section{Background}

ccording to the general census of population and housing in 2011, the population of the elderly has nearly quadrupled from
1966 to 2011 (while the population aged 60 years and older has doubled in the West). The growth rate of Iranian old people is estimated at $3.9 \%$ between 2006 and 2011. Particularly in urban areas, the elderly population has risen from 600000 in 2006 to 4.4 million in 2011. In

* Corresponding Author:

Farideh Bastani, PhD

Address: Department of Geriatric Nursing, School of Nursing \& Midwifery, Iran University of Medical Sciences, Tehran, Iran Tel: +98 (21) 43651820

E-mail: bastani.f@iums.ac.ir; faridehbastani@yahoo.com 
other words, over a period of 45 years, the urban elderly population has increased 4.7 times.

During the same period, the number of seniors of rural areas with a slower growth rate than urban areas ranged from about 1 million people in 1966 to about 1.8 million in 2010, indicating an increase of 1.7 times (Statistical Centre of Iran 2014). This difference in the growth rate can also require different needs. Moreover, the life expectancy in rural areas is less than urban areas, due to lower income, poverty, poor working conditions, lack of health facilities, traditional trusts, transportation or mobility problems, poor services or lack of access to information (Liu 2014).

Since urban elders experience a more favourable economic and health status, their needs are less than the rural elderly (Pahlavanzadeh \& Jarollahi 2011). Rural elderly people experience a higher rate of heart disease, cancer, diabetes and mortality due to diabetes, special circumstances and possibly lack of compliance with health provisions compared to urban elderly people. The difference between urban and rural population naturally creates different needs, which require different services, for example, in terms of leisure activities in rural areas and lack of these facilities (Sampaio, Ito \& Sampaio 2013).

In general, most of rural elderly people in Iran are more deprived than urban elderly in terms of available healthcare services, income, education, housing and transportation and these issues have not been addressed independently in various provinces of Iran (Statistical Centre of Iran 2014). In some studies, it has been mentioned that $18.5 \%$ of rural elderly people have serious problem with transportation in order to access to medical, social and personal needs and are far away from medical services compared to their urban counterparts. Moreover, in rural areas, safe and reliable transportation, like a mobile unit, is required to give services and required resources to rural elderly (Schwarzlose et al. 2014).

The elderly people should have access to healthcare and social services with regard to increased expenses of transportation to prevent their social isolation (Park et al. 2010). Although the experts and social workers have partly resolved this problem with their presence in health care facilities in rural areas, the condition is not the same in cities and hence, referral of the urban elderly people to healthcare centres and receiving services is significantly weaker than that in rural areas and this can make urban elderly more vulnerable than rural elderly people. Thus, it could be observed that urban or rural area of living of the elderly has its special advantages and disadvantages. Because of these differences, it is essential to investigate in the field of comparing supportive care needs of rural and urban elderly, so that increased medical expenses, unavailability of health centres and transport services can be the main problems for rural elderly and lower their life expectancy compared to urban elderly (Mousavi \& Mostafaiee 2012).

Nowadays, in majority of rural and urban communities, younger members of family are leaving their families and weakness of neighborhood networks is also increasing. As a result, some elderly people with low income, especially people in rural areas, are exposed to the risk of poverty and more subtle forms of deprivation because of transportation problems, weak services or unavailability of information (Beach \& Schulz 2017). Although majority of elderly people are still in contact with their families, the supportive institutes are responsible for meeting their needs and the requirement (Culp et al. 2016). In a study conducted in 7 European countries, it has been found that demand for social support and meeting social needs can have significant effects on improving health problems of the elderly. Those elderly people living with their spouse and family have high level of social support and less suffer from distress, depression and physical complaints. On the contrary, people with lower social support are mentally abused; low social support can associate with lower economic status and misbehavior of the elderly (Melchiorre et al. 2013).

In another work (Sampaio, Ito \& Sampaio 2013) conducted in Japan, it was found that rural elderly have less opportunity to have social interactions and supports and this can lead to low mental health. Moreover, social and emotional support can help reducing consequences of stressful events and diseases, risk factors and social isolation. In another study conducted by Bastani and Zakariaei Seraji (2012), it was found that the elderly women receive more and various supports from their network members compared to older men. The elderly men and women also act differently with providing social supports. Another result of the study was that the variables of contact and the intimacy, gender and marital status can affect social support exchange. The elderly people with face-to-face contact and more intimate relations with network members exchange more supports with them. The elderly people living in sanatoriums have stated that they stay in these places because they had no one to live with, nobody to take care of them, death of their spouse, and marriage of their children. 
Based on many studies, urban and rural elderly people consider nutritional needs and educational and nutritional supports very important Recognition of nutritional needs and also educational and nutritional support is important in urban and rural elderly people (Howie, TroutmanJordan \& Newman 2014; Culp 2016; Sampaio, Ito \& Sampaio 2013), consequently comparing the nutritional needs, along with other needs, in urban and rural elderly people is necessary. The elderly people need more support than other age groups in this field. Based on the relevant studies conducted in Iran and European countries on the health services in the elderly population, it has been shown that Iranian elderly people suffer from many problems compared to their European peers in terms of health and medical needs. Hence, to support health and treatment needs of urban and rural elderly, at first these needs should be identified and assessed and then based on these needs, authorities should start to plan for rural and urban elderly people for a holistic or comprehensive care and providing necessary support (Amiri 2014).

According to the similar studies, many factors such as social, economic and nutritional support have been studied in the elderly population; however, other needs such as healthcare, daily personal care, housing, safety, education, transport, spiritual and recreational needs that affect life of the elderly and their health status are neglected. Although lots of studies have been conducted in Iran on ageing and its complications, no study was found that compared supportive care needs of rural and urban elderly people. Congruent with urban and rural elderly population growth and an increase in the growing population of the elderly over the recent years in Iran, their more specific needs like healthcare, medical and nutritional needs have also increased.

Clearly, the analysis of needs can be an essential introduction to determine the required services of the society, identification of priorities, and optimal use of the budget (Statistical Centre of Iran 2014). Therefore, similar studies are required on supportive care needs of the elderly as well as identifying their needs and problems. In this regard, this study was conducted with the objective of comparing supportive care needs of urban and rural elderly people in Kermanshah City, Iran in 2016.

\section{Materials and Methods}

\section{Study design and participants}

It was a descriptive-comparative study. A total of 192 urban elderly and 192 rural elderly referring to rural and urban healthcare centers of Kermanshah University of
Medical Sciences were recruited by stratified random cluster sampling in 2016. To this end and determining the healthcare centers for sampling, Kermanshah was divided into 5 zones of North, South, Central, East and West. One health center was randomly chosen from each zone. Kermanshah had 25 healthcare centres in total and 5 centers were selected randomly from 5 different districts. Then, with equal proportion of each center, 40 elderly people from each center including 20 female and 20 male were selected.

Kermanshah has 27 villages distributed in 5 districts. Accordingly, elderly people who had health record in these villages were selected as sample. For data collection, a researcher-made demographic questionnaire was used containing 12 open questions related to age, gender, residence, education level, marital status, number of children, monthly income, job, insurance and staying with which family member.

\section{Support care needs questionnaire}

The supportive care need scale contains 81 items and 9 subscales including health care support (15 items and 8 options), educational support (6 items and 3 options), transport support (9 items and 3 options), personal care support (14 items and 3 options), nutritional support (8 items and 3 options), safety care support (6 items and 3 options), housing support (7 items and 3 options), spiritual support ( 7 items and 3 options), and recreational support ( 9 items and 3 options).

Scoring in this questionnaire was as follow: Overall value of each dimension shows the support gained in that field. As a result, high score in these dimensions means less need to support and lower value means more health support needs, educational, personal care, nutritional, transport, spiritual and recreational. To determine the validity of the supportive care need scale, content and face validity was used. The supportive care need scale has been assessed by 10 professors in elderly nursing fields (Amiri 2014). As the validity of supportive care need scale is assessed carefully on rural and urban elderly people and is consistent with the sample of this study, it has been used as a valid instrument for data collection in this study.

Reliability of the questionnaire was confirmed by Amiri (2014) using internal consistency. In this regard, Cronbach's alpha coefficient was calculated for health centers, education, transport, personal support, nutrition, safety, housing, spiritual and recreational needs and the related values were $0.764,0.895,0.774,0.785,0.818$, 
$0.769,0.745,0.838$ and 0.663 respectively (Amiri 2014). As reliability of the questionnaire was carefully tested on urban and rural elderly samples and is consistent with the sample of this study, it was used as a reliable data collection instrument in this study.

\section{Data analysis}

For the purpose of data analysis, SPSS-PC, (V. 22) was used. Descriptive statistics (frequency distribution tables, frequency, percent, mean value, SD and linear and numerical diagrams) and inferential statistics (chi-squared and independent t-test) were used. As the scale of responding to two subscales of spiritual and nutritional needs was quantitative, t-test was used for independent groups. However, in other subscales, chi-squared test was used to compare mean values of healthcare needs, personal care, educational, transport, security, housing and recreational needs between urban and rural elderly people.

\section{Results}

The comparison of demographic variables between two groups of urban and rural elderly people showed no significant differences in terms of gender, age, marital status and their house mates. However, they were significantly different in terms of number of children, income source, job and insurance type. With regard to the income source, $73 \%$ of urban elderly received retirement pension and were under support of supportive care organizations compared to $69 \%$ of rural elderly people.

With regard to the spiritual needs of two groups of urban and rural elderly people, there is significant difference between rural and urban elderly people $(\mathrm{P}=0.02)$ (Table 1). Regarding the nutritional needs of urban and rural elderly people, no significant difference was observed between urban and rural elderly of Kermanshah City $(\mathrm{P}=0.944)$ (Table 1).
According to the results, there is significant difference between urban and rural elderly people in terms of needs to healthcare $(\mathrm{P}=0.01)$. Regarding the personal care needs, no significant difference was seen between urban and rural elderly people of Kermanshah $(\mathrm{P}=0.068)$ (Table 1 and 2). Also, the results showed a significant difference between urban and rural elderly people in terms of educational needs $(\mathrm{P}=0.001)$. By comparing transport needs between urban and rural elderly people, significant difference was found between urban and rural elderly $(\mathrm{P}=0.01)$. Comparing security needs between urban and rural elderly people showed no significant difference between them ( $\mathrm{P}=0.43)$. With regard to housing needs, no significant difference was observed between urban and rural elderly people $(\mathrm{P}=0.71)$. Finally, after comparing recreational needs between urban and rural elderly, significant difference was observed between two groups of elderly people $(\mathrm{P}=0.001)$ (Table 2$)$.

\section{Discussion}

In terms of Demographic data such as number of children, income, occupation and type of insurance, there was a significant difference between the elderly in urban and rural areas. As mentioned before, $73 \%$ of urban elderly received retirement pension and were under support of supportive care organizations compared to $69 \%$ of rural elderly people.

The result of Maltiquera et al. study in 7 European countries, showed that $8.9 \%$ of the urban elderly were employed, $23.4 \%$ retired, 56.8\% housewives, and 9.9\% unemployed. Among the rural elderly, 25.2\% were employed, $8 \%$ were retired, $52.9 \%$ were housewives, and $11.8 \%$ were unemployed. The housewives were all female and the unemployed were all male.

In terms of spiritual support, there was a significant difference between urban and rural elders. Urban elderly people showed more spiritual needs than rural elders, and they needed to pay more attention to spirituality.

Table 1. Results of $\mathrm{t}$ test to compare spiritual and nutritional needs among urban and rural elderly people in Kermanshah

\begin{tabular}{|c|c|c|c|c|c|c|c|}
\hline Variables & & Sample Size & Mean (SD) & Mean Difference & $t$ & df & Sig. \\
\hline Spiritual needs & $\begin{array}{l}\text { Urban } \\
\text { Rural }\end{array}$ & $\begin{array}{l}192 \\
238\end{array}$ & $\begin{array}{l}15.50(4.09) \\
13.17(3.47)\end{array}$ & 2.33 & 1.21 & 229 & 0.02 \\
\hline Nutritional needs & $\begin{array}{l}\text { Urban } \\
\text { Rural }\end{array}$ & $\begin{array}{l}192 \\
238\end{array}$ & $\begin{array}{c}20.88(9.33) \\
19.32(7.88)\end{array}$ & 0.523 & 0.072 & 229 & 0.944 \\
\hline
\end{tabular}


Table 2. Results of the chi-square test to compare support needs among urban and rural elders in Kermanshah

\begin{tabular}{|cccc}
\hline Needs & $\mathbf{X}^{2}$ & df & $\mathbf{P}$ \\
\hline Healthcare needs & 8.82 & 229 & 0.01 \\
\hline Need to personal care & 1.32 & 229 & 0.068 \\
\hline Educational needs & 38.32 & 229 & 0.001 \\
\hline Transport needs & 7.86 & 229 & 0.01 \\
\hline Security needs & 2.19 & 229 & 0.43 \\
\hline Housing needs & 1.94 & 229 & 0.71 \\
\hline Recreational needs & 37.61 & 229 & 0.001 \\
\hline
\end{tabular}

This finding is consistent with the findings of Babanzade et al. (2012) in Ilam City, Iran that $30 \%$ of women and $70 \%$ of elderly men referred to mosques and pilgrimage centers, as well as $27.7 \%$ of women and $72.3 \%$ of rural elderly men participated in reading prayers and Quran, with a significantly higher number of men than women.

In explaining this finding, it can be argued that elderly people in large cities usually face more problems, like machine life, high occupancy of family members, work-life problems, and careless children who usually do not spend time to address the spiritual needs of the elderly. Urban people can access the mosque during the prayer so they pray less than the rural people, on the other hand, in a small village and the centrality of the mosque, villagers are more engaged in prayers for the congregation and the use of spiritual spaces. Older people living in rural areas compensate for spiritual needs by engaging more with their neighbors and friends. The positive aspects of living in the countryside, such as the stability of the inhabitants and their shared values and lifestyles, boost social relations. From the theoretical point of view, religious beliefs in rural elders contribute to their adjustment to stresses and can influence seniors' evaluations of events.

There was no significant difference between urban and rural elderly in terms of nutritional needs. In this regard, the urban and rural elderly were equal in all aspects of nutrition. This finding is in line with the results of Kansal et al. (2016) study entitled "Assessment of Nutrition Support Status of 190 Rural Indigenous People in India." They found that a minority of women had normal nutritional status indicating the support needs of this part of the rural community to the nutritional issue; however, they did not find any significant relationship between the gender of the elderly and their nutritional status.
In terms of health care needs, there was a significant difference between urban and rural elders and it was shown that urban elderly have more health care needs. This finding is somewhat inconsistent to the results of the Schwarzlose et al. (2014) study, which showed that $18.5 \%$ of the rural elderly did not receive any health care from the healthcare centers. In explaining this difference, rural elders in the Schwarvels study had a serious problem with transportation to access medical, social and personal needs, and they usually had more distance from medical services than their urban counterparts.

In rural areas, transportation is safe and reliable, for example, providing rural elderly services, like a mobile unit, is necessary to access the needed resources. But in our study, healthcare centers in villages have somewhat resolved this gap. In explaining the high health care needs of urban elderly people, one can highlight the level of expectations and high quality of life in the city and the urban elderly, which compels older people to expect higher level standards when answering the questions of the need support questionnaire. As a result, their unsatisfied support needs increase.

On the other hand, dissatisfaction among urban elderly people can increase their support needs. The cost of living in the city is very high and most commodities in the city are very expensive. Also, the findings of the present study are inconsistent with the results of studies of Lowry (2009) in China, Howie et al. (2011) in Tierney et al. (2015) in Australia that rural elderly have less access to health care compared to those who live in the city. This could be related to the cultural differences and different possibilities of the two countries and the city studied. In terms of need for personal care, there was no significant difference between urban and rural elders, but in dimensions such as interaction and sleep, elderly people 
showed a better situation. These findings were in agreement with the results of Babanejad et al. (2013) study.

In a study in 2012 on elderly people in Ilam Province, a few elderly people found it difficult to wear and change clothes in their bathing and personal grooming. In explaining these findings, it can be said that older people who are in poor health and keep in touch with their friends through personal contact, have better mental health and show less sleep disturbances. Similarly, when close relatives die, friends can compensate for their lack of social support. In explaining this finding, one can argue that the elderly living in small towns and rural areas, by interacting more with the neighbors and friends, compensate for the distance from family members and social services. The positive aspects of small communities, such as the stability of their inhabitants, and their shared values and lifestyles, enhance the happy social relationships (Mortazavi et al. 2011).

The results of this study show that rural elders receive more education and urban elderly people need more attention with regard to educational needs. This finding is in line with the results of the study by Flia et al. (2007). They found that non-medical strategies such as diet and exercise training can improve blood glucose levels, increase patient's motivation, prevent complications of disease, and promote quality of life in the rural elderly. In explaining these findings, it can be noted that urban elderly have problems such as transportation, i.e., being far away from health centers and educational centers compared to their rural counterparts.

The findings of this study show that transportation needs in urban elderly people of Kermanshah are significantly higher than that in rural elderly people. The results of this study, to some extent, were congruent with a research on the elderly in Iran. Bagheri Dizay et al. (2013), found that $62.9 \%$ of people were able to use public transport and $14.2 \%$ could not use the vehicle at all. The results of Averil (2012) in one of New Mexico's villages in the United States showed that rural elders face serious transportation problems and thus no access to medical, social and welfare services. These findings are consistent with the results of our study.

The results of this study show that urban elders have more spiritual needs than rural elderly people. But rural elderly people need more health care, education, transportation and recreational facilities. In terms of nutritional needs, personal care, housing and safety, there was no significant difference between urban and rural elderly people. According to these findings, recreational facili- ties are essential for the elderly. It is also important to increase the level of literacy especially in villagers in order to increase their social interactions and promote the use of social networks to prevent social isolation. Therefore, considering more vulnerability of rural elderly people compared to their urban counterparts, it is necessary to pay attention to the needs of this group. Also, attention to health issues and the availability of health care facilities are priorities that should be considered more seriously for elderly population.

\section{Ethical Considerations}

\section{Compliance with ethical guidelines}

All procedures performed in studies involving human participants were in accordance with the ethical standards of the institutional research committee and with the 1964 Helsinki declaration and its later amendments or comparable ethical standards. Informed consent was obtained from all individual participants included in the study. The study had obtained the approval by Ethics Committee of Iran University of Medical Sciences before conduct (No: IR.IUMS.REC 1395.9311580011).

\section{Funding}

This article has been adopted from the Master thesis of first author submitted to Department of Geriatric Nursing in School of Nursing and Midwifery of Iran University of Medical Sciences. The study was supported by the Research Vice Chancellor in Iran University of Medical Sciences, Tehran, Iran.

\section{Conflict of interest}

The authors declared no conflict of interest.

\section{Acknowledgements}

We would like to thank and appreciate the urban and rural elderly people in Kermanshah City, who participated in this research.

\section{References}

Amiri, M., 2014. [Comparative study of support needs of urban and rural elderly people in Gonabad City, 2014 (Persian)] [MSc. thesis]. Isfahan: Islamic Azad University, Khorasgan Branch. 
Averill, J. B., 2012. Priorities for action in a rural older adults study. Family \& Community Health, 35(4), pp. 358-72. [DOI:10.1097/FCH.0b013e318266686e]

Babanejad, M., et al., 2013. [Socioeconomic status of aged people in Ilam Province (Persian)]. Research in Medicine. 37(2), pp. $125-33$.

Bacsu, J. R., et al., 2012. Healthy aging in place: Supporting rural seniors' health needs. Online Journal of Rural Nursing and Health Care, 12(2), pp. 77-87.

Baernholdt, M., et al., 2012. Quality of life in rural and urban adults 65 years and older: Findings from the national health and nutrition examination survey. The Journal of Rural Health, 28(4), pp. 339-47. [DOI: 10.1111/j.1748-0361.2011.00403.x]

Bagheri Dizaj, M., et al., 2015. [The relationship between dietary patterns and mild cognitive impairment in retired elderly women in Tehran (Persian)]. Medical Journal of Mashhad University of Medical Sciences, 58(10), pp. 590-602. [DOI:10.22038/ MJMS.2016.6787]

Bastani, S., Zakariaee Seraji, F., 2012. [Gender differences in old age: Networks and social supports. Journal of Social Problems of Iran, 3(1), pp. 33-57.

Beach, S. R. \& Schulz, R. 2017. Family caregiver factors associated with unmet needs for care of older adults. Journal of the American Geriatrics Society, 65(3), pp. 560-6. [DOI:10.1111/ jgs.14547] [PMID]

Culp, S., et al., 2016. Unmet supportive care needs in US dialysis centers and lack of knowledge of available resources to address them. Journal of Pain and Symptom Management, 51(4), PP. 756-61. [DOI:10.1016/j.jpainsymman.2015.11.017] [PMID]

Filia, A., et al., 2007. Health burden and economic impact of measles-related hospitalizations in Italy in 2002-2003. BMC Public Health, 7(1), p. 169. [DOI:10.1186/1471-2458-7-169] [PMID] [PMCID]

Howie, L. O., Troutman-Jordan, M. \& Newman, A. M. (2014). Social support and successful aging in assisted living residents. Educational Gerontology, 40(1), pp. 61-70. [DOI:10.1080/ 03601277.2013.768085]

Kansal, D., et al. (2016). Nutritional assessment among elderly population of rural Belagavi: A cross-sectional study. International Journal of Medical Science and Public Health, 5(7), pp. 14969. [DOI:10.5455/ijmsph.2016.15122015298]

Liu, J., 2014. Ageing, migration and familial support in rural China. Geoforum, 51, pp. 305-12. [DOI:10.1016/j.geoforum.2013.04.013]

Lowry, D., 2009. Aging, social change, and elderly well-being in rural China: Insights from mixed-methods village research. Michigan: Population Studies Center, University of Michigan.

Martin, J., et al. 2016. Recruiting US Chinese elders in to clinical research for dementia. Alzheimer Disease and Associated Disorders, 30(4), pp. 345-7. [DOI:10.1097/WAD.00000000000000162] [PMID] [PMCID]

Melchiorre, M. G., et al., 2013. Social support, socio-economic status, health and abuse among older people in seven European countries. Plos One, 8(1), p. e54856. [DOI:10.1371/journal.pone.0054856]
Mortazavi, S. S., et al., 2011. [Mental health of Shahrekord's elderly and its relationship with demographic and social factors (Persian)]. Payesh, 10(4), pp. 485-92.

Mousavi, M. \& Mostafaiee, A., 2012. [Analysis of the quality of life of retired elderly in Tehran with an emphasis on formal and informal social support (Persian)]. Social Development $\mathcal{E}$ Welfare Planning, 2(7), pp. 137-64.

Pahlavanzade, F., \& Jarollahi, O., 2011. [Effect of social factors on mental health of rural elderly (Persian)]. Journal of Community Development, 3(1), pp. 65-84.

Park, N.S., et al., 2010. Transportation difficulty of black and white rural older adults. Journal of Applied Gerontology, 29(1), pp. 70-88. [DOI:10.1177/0733464809335597]

Sampaio, P. Y. S., Ito, E. \& Sampaio, R. A. C., 2013. The association of activity and participation with quality of life between Japanese older adults living in rural and urban areas. Journal of Clinical Gerontology and Geriatrics, 4(2), pp. 51-6. [DOI:10.1016/j.jcgg.2012.11.004]

Schwarzlose, A. A. I., et al., 2014. Willingness to pay for public transportation options for improving the quality of life of the rural elderly. Transportation Research Part A: Policy and Practice, 61, pp. 1-14. [DOI:10.1016/j.tra.2013.12.009]

Sheikh, S., et al., 2013. [Comparison between the risky agents correspond to fall in elderly people of urban and rural regions of Zabol (Persian)]. Iranian Journal of Aging, 8(3), pp.44-52.

Siegel, S. \& Castellan, N. J. 1988. Nonparametric ststistics for the behavioral scienses. New York: McGraw Hill.

Statistical Centre of Iran., 2014. Statistical pocketbook of the Islamic Republic of Iran 1390 (Iranian Year) (March 2011-March 2012) NO. 28. Tehran: Statistical Centre of Iran.

Tierney, P., Freeman, S. \& Gre Gory, J., 2015. 11 Caring for the acutely Ill adult. In: Burns, D (ed), Foundations of adult Nursing. Thousand Oaks, California: SAGE Publications. 
